\title{
Notes on glycogen deposits in Limnaea auricularia var. rufescens and the parasitic larval stages of Fasciola gigantica and Ecbinostoma revolutum
}

\author{
A Histochemical Study
}

\author{
par M. M. PATNAIK
}

State Veterinary Laboratory, Bhubanewar 3. India

\begin{abstract}
Résumé
Par la technique du PAS, les dépôts de glycogène dans divers tissus de Limnaea auricularia var. rufescens, infestées par les stades larvaires de Fasciola gigantica ou d'Echinostoma revolutum, ont été signalés.

Les localisations histologiques des réserves de glycogène chez des limnées de cette espèce, soit neuves, soit infestées, soit infestées et privées de nourriture, ont été étudiées comparativement.

L'affectation d'une partie du glycogène de l'hôte au développement des larves infestantes ou simplement son dépôt chez ces larves sont brièvement indiqués.
\end{abstract}

\section{Summary}

By employing PAS technique, the intravitam glycogen deposits in various tissues of the snail, L. auricularia var. rufescens, infected with the larval stages of either $F$. gigantica or $E$. revolutum in different locations was sudied. The sites of glycogen reserves in uninfected, uninfected and starved, and infected snails were compared. Relative deployment of iglycogen reserves from the host tissue for development or deposition in the larval trematodes was briefly indicated.

This study was supported in part by a Research grant from the Board of Scientific and Industrial Research, Orissa $\left(\mathrm{N}^{\circ} 5\right)$. 
Recently the histological observations on the relative pathogenic effects produced by the larval stages of Echinostoma revolutum, Fasciola gigantica and other trematodes in Limnaea auricularia var. rufescens have briefly been described (Patnaik and Ray 1966, 1968). This presentation concerns the observations made on the presence and sites of deposition/depletion of glycogen reserves in L. auricularia var. rufescens parasitized with either $F$. gigantica or $E$. revolutum and uninfected starved snails from histochemically treated sections, with emphasis on distinctive features.

\section{Materials and Methods.}

From a collection of snails belonging to L. auricularia var. rufescens of one locality, six infected with $F$. gigantica, five infected with $E$. revolutum and five uninfected snails were selected. Of them, three uninfected snails were allowed to starve in water for five days in the laboratory. All were uniformly deshelled, fixed in formaline, embeded in paraffin and serially sectioned 7-10 microns thick. Periodic-Acid-Schiff's (P.A.S.) technique was employed for staining one of every three slides and of the two inbetween remaining slides, one was subjected to saliva or diastase $(1 \%)$ action for one hour at $37^{\circ} \mathrm{C}$ and stained by P.A.S. method for use as control, and the other was stained with Hematoxyline and Eosin to study the structures in detail.

In some selected cases alcohalic saturated iodine solution (for 10 minutes) was used for iodine test before they were stained with Hematoxyline and mounted in glycerine-jelley for confirmation of the P.A.S. positive material as glycogen. Ziehl-Neelsen'ls carbol fuchsin and Gram's stain was conducted in few cases.

\section{Observations.}

The P.A.S. positive materials of untreated slides were distinct from the saliva (diastase) treated control slides, where in the positive reaction for polysaccharide was weak or lost. As iodine also imparted a mohogany brown colour to the substances, corresponding to the diastase labile P.A.S. positive materials in other slides, in pale yellow back ground they were considered as giycogen. Those material although gave a P.A.S. positive reaction, but not digested in saliva were not considered as glycogen. Such glycogen reserve was invariably found in diffuse or finely granular form in the hepatopancreatic cells, other secretory gland cells and epithelial lining of duct wall, intestine wall, mantle collar, body musculature and some times in circulating hemolymph in the racemosus hepatic acini. The depletory (glycolytic) changes in the infected snails appeared to preceed other necrobiotic changes and continue simultaneously with the progressive changes. The degree of glycogen depletion from the host tissue in general was found to be in proportion with the size and state of infection.

Hepatopancreas: The gland cells of the hepatopancreas of uninfected snails were rich in uninformly distributed glycogen granules and in starved snails of laboratory, contained glycogen in clumps more towards the apical parts than at its basal portion. The secretory mucinous material were weakly P.A.S. positive. The hepatic cells 


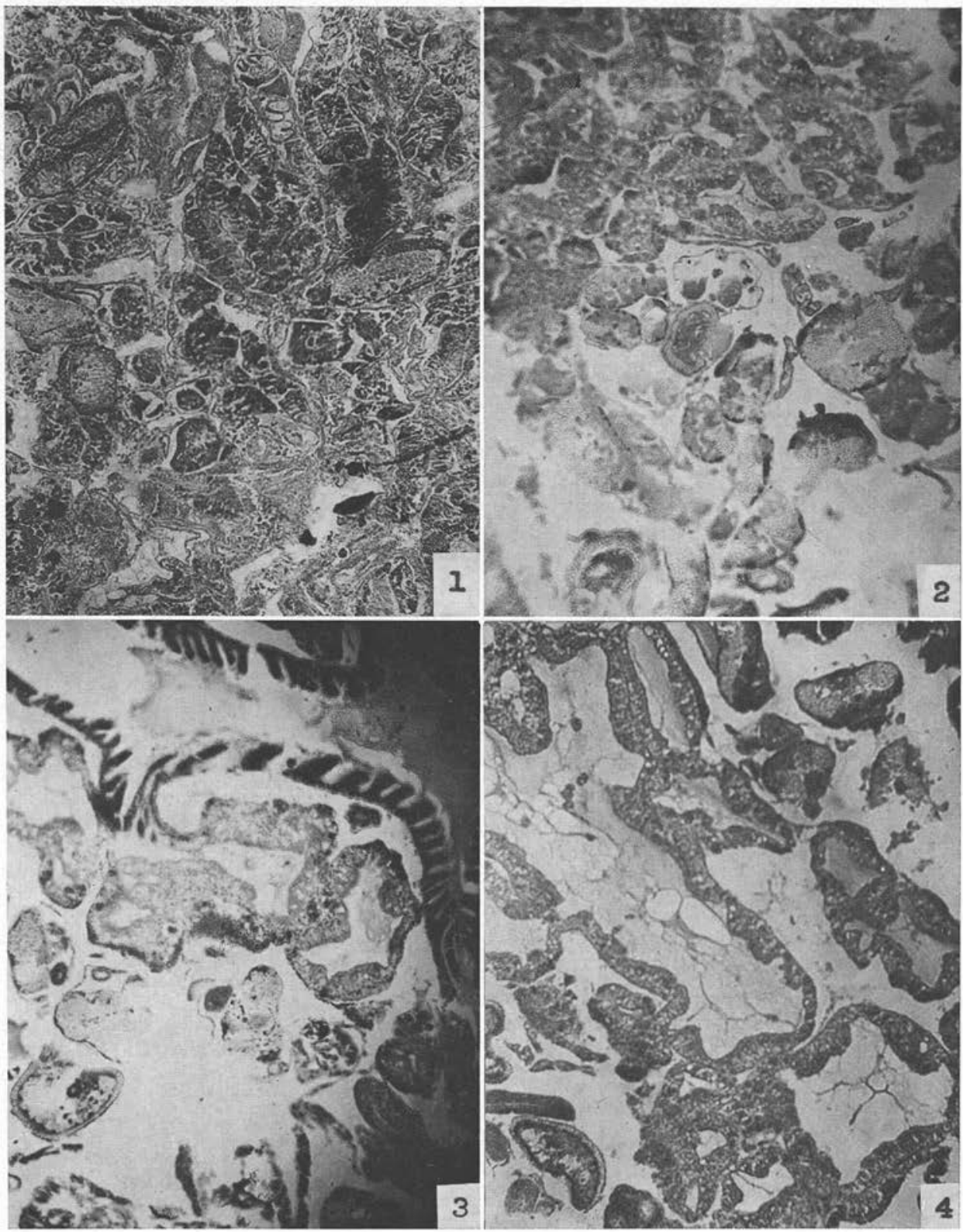

FIG. 1. - Photomicrograph of a section of hepatopancreas of the snail infected with early larval stages of F. gigantica showing heavily stained PAS positive material in the parasitic forms and lightly stained host gland cells. Note the parasites which are in close contact in the host tissue (PAS reaction X 80)

FIG. 2. - Photomicrograph of a portion of hepatopancreas of the snail infected with more developed larval stages of $F$. gigantica. Note cellular degeneration and loss of cytoplasmic content of the hepatic cells in the vicinity and glycogen clumps in the luminal boundary of the hepancreatic cells in the distantly located acini. (PAS reaction X 80)

FIG. 3. - Photomicrograph of a longitudinal section passing through the hepatopancreatic duct showing developed free cercariae of $F$. gigantica in the interacinar space. Note darker stained PAS positive material in the epithelial lining. Secretions of the hepatopancreatic duct, and secretions inside. (PAS reaction X 80)

FIG. 4. - Photomicrograph of a section of hepatopancreas of the snail infected with the larval stages of $F$. gigantica. Note the oedematous changes of the gland, empty defatted spaces and PAS negative, yellowish brown acid fast capsules in the hepatic cells of the acini (PAS reaction X 80) 
of snail having light infection manifested similar changes as found in starved ones but the localised changes, around those containing the early developing stages and daughter rediae, was depletion of glycogen from adjescent cells. The parasitic stages, which remained packed in glandular tissue contained more deeply stained diastase labile P.A.S. positive material and exerted obvious mechanical changes due to pressure around them (fig. No. 1 et 5). In heavily infected snails having complete cellular degeneration, there was loss of distinct cytoplasmic content and cell shape in the vicinity, and afore mentioned changes in the distantly located acini. The luminal boundary of nearer acini was least distinct and vacuolated (fig. No. 2 \& 4).

Alimentary tract: The gastro-intestinal epithelial lining were strongly P.A.S. positive in well-fed and uninfected snails than those in infected or starved snails. Salivary glands and connective tissue matrix around them did not manifest any significant change. The hepatic duct lining epithelium also manifested changes similar to thse of the gut lining epithelium (fig. No. 3).

Muscle tissue: The muscular tissue of uninfected snail was more compact and contained uniformly distributed diffuse P.A.S. positive substances and intensely stained muscle fibre. The surface epithelium, sub-epithelial locations, and the pedal mucous gland cells were invariably rich in P.A.S. positive material. In infected or starved snails, the deeper muscular tissue was weakly P.A.S. positive but there was no significant change in perpherial parts. In snails whose muscle tissue or mantle collar have been heavily infected by the larval stages had encircling fibroblasts around the parasitic stages, which took up comparatively heavier stain than surrounding tissue (fig. No. 8).

Other locations: Body secretions in tissue spaces, hemolymph, ducts of infected or starved snails contained acelluar P.A.S. positive material in snails having light infections. The connective tissue and other accessory/secretory glands were weakly P.A.S. positive (fig. No. $6 \&$ \%). In heavily infected cases, host tissue of the infected parts was completely replaced by the parasitic stages.

Parasitic larval trematodes: The intial basophilic sporocystic stages and younger rediae filled with germ balls contained no appreciable/detectible amount of glycogen deposition. The rediae containing cercariae had P.A.S. postive material in the myofibrils of suckers, inner body lining and its gut wall (fig. No. 6). The gut of the migratory, tissue devouring rediae contained P.A.S. positive ingesta. Increased amount of glycogen was found in the soma of cercariae, quite in proportion with the relative degree of their development. The chief sites of glycogen deposition in cercariae were at myofibrils of both suckers, parenchymatous cells, lining epithelium of the rudimentary alimentary tract, penetration glands and other undifferentiated locations. Except in the myofibrils of suckers in rediae and cercaria, where the glycogen reserve was uniformly distributed, amorphous masses of glycogen in large clumps was found in the parenchyma of the cercariae. The tail contained uniformly distributed glycogen but not in significant amount (fig. No. 4 \& 7). The emerging forms of cercariae contained maximum amount of glycogen and were more intensely stained than the host-tissue. 


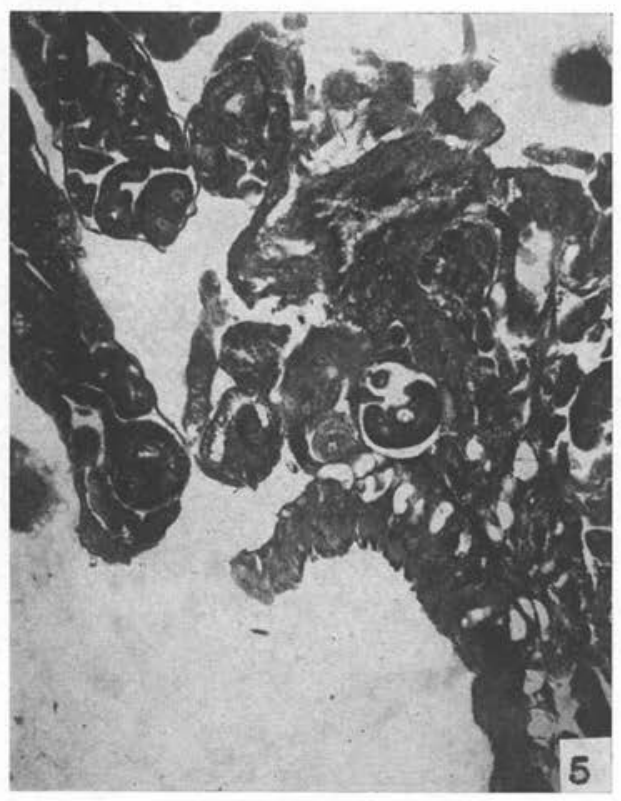

FIG. 5. - Photomicrograph of a section of hepatopancreas and its binding connective tissue lining of the snail infected with the larval stages of $E$. revolutum. Note the intensely PAS positive parasitic stages more uniformly distributed. (PAS reaction $\mathrm{X} 80$ )

In the cercariae of $F$. gigantica the peripheral thick eosinophilic cystogenous material were P.A.S. negative. The P.A.S. positive material (glycogen) were seen in much larger clumps underneath the cytogenous layer more towards the back and sides, suckers and below the acetabulum (fig. No. 4). The excretory canals and globules were P.A.S. positive both in saliva treated and untreated slides.

In the cercariae of E. revolutum, P.A.S. positive granules were sparsely distributed in the parenchymatous tissue. The cystogenous glands were less prominant and thin. The deposition were more towards the dorsal aspect. The undifferentiated locations on either side of acetabulum and in the region of genital primordia, were equally and intensely positive for glycogen (fig. No. 5). The encysted metacercariae in the muscular tissue contained less amount of glycogen than in cercariae but were fairly richer than the surrounding tissue. However, their distribution in the metacercariae were same as in cercariae (fig. No. 8).

Besides the above common changes, the specific changes include, more degrading glycolytic changes in $E$. revolutum infection than in $F$. gigantica infection. In $F$. gigantica infection concurrent fatty changes were significant and many rounded defatted empty spaces appeared in hepatic cells. There were some acid fast gram negative, yellowish brown capsule like basally located intracellular structures in the hepatic acini of $F$. gigantica infected snails. Few such capsules also contained small globular homogenous structures of 2-4 microns diameter. Local effects of parasitism were more significant in $F$. gigantica infection than in E. revolutum infected ones with oedematous changes in hepatopancreas (fig. No. 4). 
Discussion.

Microscopically discernible intravitam glycogen in the fixed tissue do not represent the actual stages in which they occur in living tissue (probably in a liquid state) but is the preciptated product. According to Gomri (1952). alcohal as fixative cause aggregation of glycogen into fairly coarse droplets while formaline reveal a more uniform finely granular distribution of glycogen. In the present study, all tissue uniformly fixed in formaline gave more dependable results and offered distinctive informations on precipitation of glycogen in different tissues.

The intramolluscan stages of larval trematodes, for their development in an anaerobic environment, derive their carbonhydrate nutrients from the glycogen reserves of the host. The comprehensive review and work of Oheng and Snyder (1962) and Cheng (1963) provided an idea of distribution of the intravitam glycogen (diastase labile P.A.S. positive material) and the process of glycogen deployment from the host tissue for the development of parasitic larval trematodes. Specific study in the snail, L. auricularia var. rufescens also suggest, in addition to Hurst's (1927) observations of over all reduction of glycogen content in muscular and hepatopancreatic tissue, that the granular deposits of glycogen were initially and directly influenced and diffuse deposits of muscular tissue were indirectly influenced by the larval stages of either trematodes.
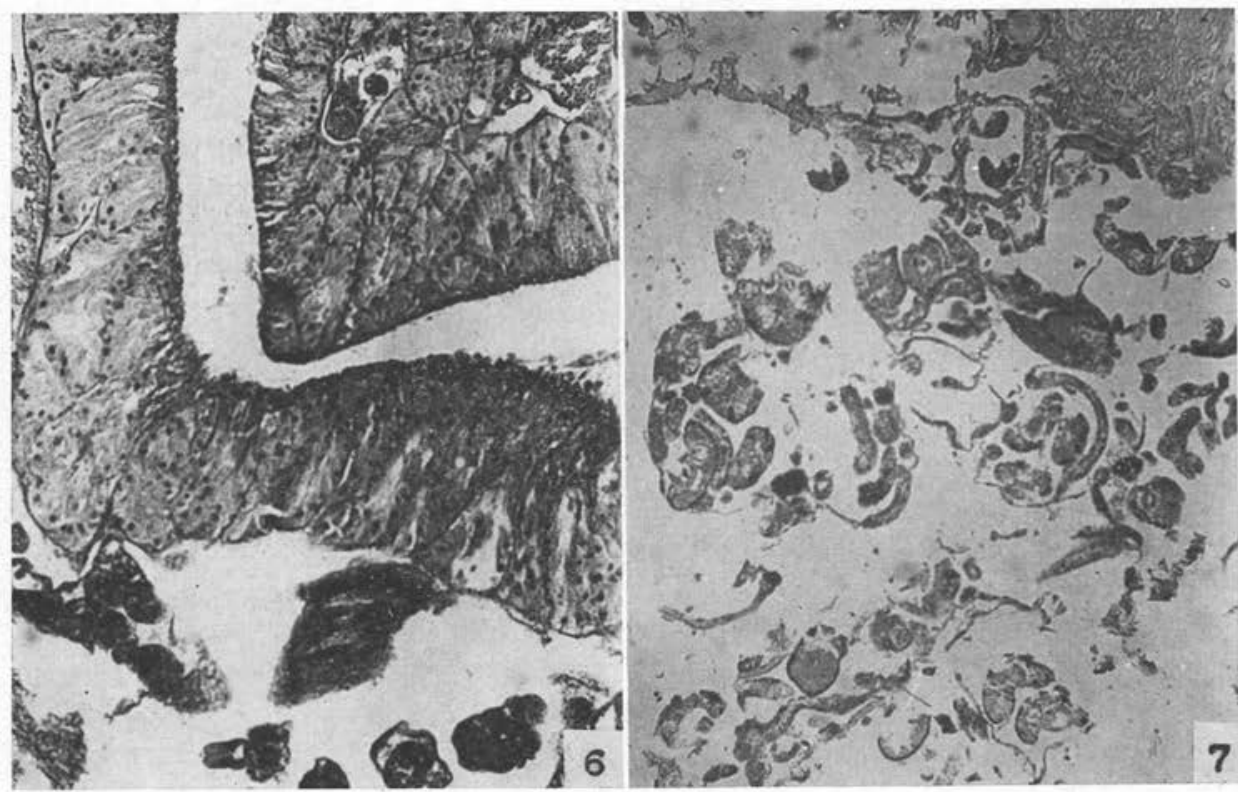

FIG. 6. - Photomicrograph of a portion of gonad of the snail showing the invading radiae of $E$. revolutum. Note the darker parts which represent glycogen in the myofibrils of suckers and peripheral part of the gland. (PAS reaction X 80)

Fig. 7. - Photomicrograph of a section passing through the disintegrated radiae containing more developed stages of $E$. revolutum in the connective tissue spaces, of the snail. Note weakly PAS positive connective tissue matrix and body wall of the cercariae. (PAS reaction X 80) 


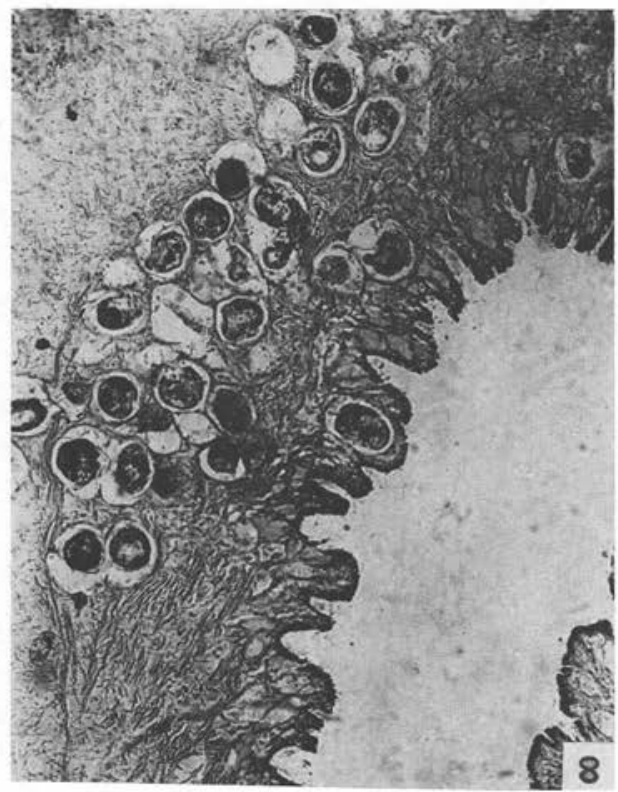

Fig. 8. - Photomicrograph of a peripheral portion of the muscular foot of the snail showing the encysted metacercariae of $E$. revolutum in sub-epithelial heavily PAS positive locations. Note the glycogen deposit in and around the encysted forms. (PAS reaction X 80)

The glycogen rich hepatopancreas greatly support and aid maturation, and release of cercariae. The emerging cercariae from such locations contained maximum amount of glycogen. The effect of starvation in the snail was more or less similar, with regard to the glycogen content, to those in infected one.

Essentially the depletary changes in glycogen reserve of host tissue and deposition in the larval stages in case of both kind of trematodes is similar but less significant in $F$. gigantica. The accompanying fatty changes (to be described later) and oedematous glyceamic changes in $F$. gigantica infected snail were more significant. The unidentified yellowish brown P.A.S. negative intracellular structures in defatted hepatic tissue were distinct from the brown cells, but the yellowish spheroids are most likely identical with those described by Cheng and Burton (1965).

\section{Références}

Cheng (C. T.), 1963. - Biochemical requirements of larval trematodes. Ann. N.Y. Acad., Sci., $113: 289-321$.

- and Burton (R. W.), 1966. - Relationship between Bucephalus sp. and Crossostrea virginica; a histochemical study of some carbohydrates and carbohydrate complexes occurring in the host and parasite. Parasitology, 56: 111-122.

- and SNYDER (R. W. Jr.), 1962. - Studies on host parasitic relationships between larval trematodes and their hosts. 1. A review. 2. The utilisation of hosts glycogen by the 
intra molluscan larvae of Glypthelmins pennyslvaniensis and associated phenomena. Trans. Amer. Microsc. Soc., 81 : 209-288.

GoMRI (G.), 1952. - Microscopic histochemistry. University of Chicago, press, p. 273.

HURST (C. T.), 1927. - Structural and functional changes produced in the gastropod molluses, Physa occidentalis in the case of parasitism by the larvae of Echinostoma revolutum. Univ. Cal. Publ. Zool., 29: 321-404.

PATNAIK (M. M.) and RAY (S. K.), 1966. - A histologic study of Lymnaea auricularia var rufescens infected with the larval stages of Echinostoma revolutum. Jap. J. Med. Sci. Biol., 19: 253-258.

- , - 1968. - Studies on geographical distribution and ecology of Lymnaea auricularia var. rufescens the intermediate host of Fasciola gigantica in Orissa, Indian. J. Vet. Sci., $38: 498-522$.

Acknowledgment : The author is grateful to the Director of Animal Husbandy and Veterinary Services, Orissa, for the facilities provided. 